\title{
PENGARUH ATMOSFER RITEL DAN PROMOSI TERHADAP IMPULSE BUYING YANG DIMEDIASI EMOSI POSITIF
}

\author{
A A Bagus Jambe Negara ${ }^{1}$ \\ Ni Made Wulandari Kusumadewi ${ }^{2}$ \\ ${ }^{1,2}$ Fakultas Ekonomi dan Bisnis Universitas Udayana, Bali, Indonesia \\ e-mail: jambenegaraa@gmail.com
}

\begin{abstract}
ABSTRAK
Tujuan penelitian ini adalah untuk menjelaskan pengaruh atmosfer ritel, dan promosi terhadap emosi positif, pengaruh atmosfer ritel, promosi, dan emosi positif terhadap impulse buying, peran emosi positif sebagai pemediasi atas hubungan antara atmosfer ritel dan promosi terhadap impulse buying pada konsumen Hypermart Carrefour Denpasar. Populasinya adalah seluruh konsumen yang pemah berbelanja dan melakukan Impulse Buying di Hypermarket Carrefour Denpasar. Metode penentuan sampel yang digunakan adalah purposive sampling sehingga didapat jumlah sampel 112 responden. Teknik analisis data menggunakan analisis jalur. Hasil penelitian menunjukkan bahwa secara parsial atmosfer ritel, dan promosi berpengaruh positif terhadap emosi positif. Secara parsial atmosfer ritel, promosi, dan emosi positif berpengaruh positif terhadap impulse buying. Emosi positif memediasi hubungan antara atmosfer ritel dan promosi terhadap impulse buying pada konsumen Hypermart Carrefour Denpasar.
\end{abstract}

Kata Kunci: atmosfer ritel, promosi, emosi positif, impulse buying

\begin{abstract}
The purpose of this study is to explain the influence of retail atmosphere, and promotion of positive emotions, the influence of retail atmosphere, promotion, and positive emotions on impulse buying, the role of positive emotions as mediating the relationship between the retail atmosphere and the promotion of impulse buying on consumers of Hypermart Carrefour Denpasar. Its population is all consumers who have been shopping and doing Impulse Buying in Hypermarket Carrefour Denpasar. The method of determining the sample used was purposive sampling so that the sample number of 112 respondents was obtained. Data analysis technique using path analysis. The results show that partially retail atmosphere, and promotion positively affect positive emotions. Partially the atmosphere of retail, promotion, and positive emotions have a positive effect on impulse buying. Positive emotions mediate the relationship between the retail atmosphere and the promotion of impulse buying on consumers of Hypermart Carrefour Denpasar.
\end{abstract}

Keywords: retail atmosphere, promotion, positive emotions, impulse buying 


\section{PENDAHULUAN}

Pertumbuhan perekonomian dan perkembangan zaman yang semakin modern, berdampak pada pergeseran budaya berbelanja masyarakat di Indonesia. Fenomena ini dapat dibuktikan dengan adanya perubahan gaya hidup masyarakat yang dahulu berbelanja di pasar tradisional, namun saat ini masyarakat Indonesia lebih suka berbelanja di ritel modern seperti swalayan, hypermarket, minimarketdan department store. Pergeseran pola konsumsi masyarakat yang berubah seiring dengan peningkatan pendapatan masyarakat, menyebabkan peningkatan pada kebutuhan masyarakat. Perilaku konsumen tersebut merupakan salah satu faktor pemicu berkembangnya bisnis ritel modern di Indonesia.

Berdasarkan data yang di peroleh pada tahun 2010 jumlah outlet modern market telah mencapai 11,300 unit retail modern. Perkembangan omzet ritel diprediksikan hingga Rp.2,32 triliun pada tahun 2016 dari Rp.1,39 triliun pada tahun 2011 (Hindarmara, http://www.frontier.co.id,2013). Ritel modern memberikan banyak tawaran seperti suasana toko yang nyaman, kegiatan promosi dan display produk yang menarik sehingga dapat menciptakan emosi positif pada diri konsumen untuk melakukan pembelian secara spontan. Industri ritel modern merupakan industri yang strategis dan memberikan kontribusi terhadap peningkatan perekonomian Indonesia.

Meskipun peluang cukup terbuka, namun tetap saja menjadi tantangan tersendiri bagi pelaku bisnis ritel karena dengan semakin dinamisnya persaingan bisnis ritel maka para pelaku bisnis ritel harus lebih kreatif dalam menyusun strategi pemasaran agar dapat menarik lebih banyak konsumen, karena dengan 
A A Bagus Jambe Negara dan Ni Made Wulandari Kusumadewi, Pengaruh Atmosfer.....

banyaknya pilihan ritel modern yang sejenis, konsumen akan cenderung membandingkan dan dengan mudah memilih ritel mana yang dianggap memberikan tawaran yang lebih menarik dari sisi harga, kualitas pelayanan maupun fasilitas yang disediakan. Hypermarket, supermarket, dan minimarket merupakan bentuk-bentuk ritel modern yang terdapat di Kota Denpasar, dimana terdapat 295 minimarket, 2 Hypermarket, dan 41 supermarket yang aktif dan menyediakan segala kebutuhan masyarakat Kota Denpasar.

Hypermarket Carrefour merupakan Hypermarket yang berlokasi di JL. Sunset Road, Banjar Glogor Carik, Desa Pemogan, Denpasar - Bali. Carrefour Hypermarket merupakan salah satu Hypermarket terbesar yang terdapat di Kota Denpasar. Carrefour Hypermarket menawarkan barang-barang yang lengkap dalam pilihan berbelanja dari barang kebutuhan sehari-hari, barang elektronik, pakaian, dan peralatan olahraga. Alasan memilih Carrefour Hypermarket sebagai objek penelitian, karena Carrefour Hypermarket menawarkan fasilitas yang lebih lengkap dan area toko yang luas sehingga seluruh barang yang di butuhkan oleh konsumen terdapat di dalam Hypermarket.

Carrefour Hypermarket bisa dikatakan Hypermarket yang sering memberikan diskon, menyediakan lapangan parkir yang luas, dan keramahan para karyawan dalam melayani konsumen. Hal inilah mendasari banyak konsumen di Kota Denpasar yang melakukan pembelanjaan di Carrefour Hypermarket. Dalam survey yang dilakukan terhadap 20 orang responden yang mengunjungi Carrefour Hypermarket, diperoleh hasil bahwa keseluruhan konsumen pernah melakukan impulse buying pada saat berbelanja pada Carrefour Hypermarket di Kota 
Denpasar. 14 responden menyatakan bahwa promosi berpengaruh meningkatkan impulse buying dan 8 responden lainnya menyatakan susasana toko yang nyaman mampu meningkatkan impulse buying. Hal ini mengindikasikan bahwa fenomena impulse buying selalu terjadi pada saat konsumen berbelanja di Carrefour Hypermarket.

Perilaku berbelanja masyarakat yang semakin modern saat ini, lebih mengacu pada suasana gerai oleh sebab itu perlu diperhatikan mengenai penciptaan suasana toko atau store atmosphere yang menarik. Utami (2010:69) mengungkapkan salah satu penyebab terjadinya pembelian impulsif merupakan pengaruh stimulus dari lingkungan gerai. Menurut Sultan et al. (2012) pembelian impulsif merupakan sebuah dorongan yang kuat untuk membeli sesuatu dengan segera yang lebih bersifat emosional daripada rasional.

Perilaku impulse buying cenderung mendominasi perilaku pembelian yang dilakukan oleh konsumen pada saat ini (Naentiana dan Setiawan, 2014). Impulse buying adalah fenomena umum di pasar dan telah menjadi titik fokus bagi kegiatan pemasaran (Graa et al., 2014). Impulse buying merupakan tindakan membeli yang sebelumnya tidak diakui secara sadar sebagai hasil dari pertimbangan, atau niat membeli yang terbentuk sebelum memasuki gerai atau bisa juga dikatakan suatu desakan hati yang tiba-tiba dengan penuh kekuatan, bertahan dan tidak direncanakan untuk membeli sesuatu secara langsung, tanpa banyak memperhatikan akibatnya (Mowen dan Minor, 2002). Impulse buying sering terjadi karena adanya perasaan emosi dari konsumen pada saat berbelanja di suatu gerai. 
A A Bagus Jambe Negara dan Ni Made Wulandari Kusumadewi, Pengaruh Atmosfer.....

Terkait dengan pembelian impulsif itu sendiri, terdapat beberapa faktor yang dapat menyebabkan terjadinya pembelian impulsif di dalam toko. Pembelian tidak terencana dapat ditimbulkan akibat adanya rangsangan dari lingkungan toko salah satunya adalah atmosfer ritel. Menurut Gilbert (2003:129), atmosfer ritel adalah perubahan yang dibuat pada desain dari lingkungan membeli yang menghasilkan efek emosional khusus yang kemudian meningkatkan kemungkinan bahwa pembelian akan berlangsung. Keadaan emosi konsumen dipengaruhi Store Atmosphere yang menyebabkan atau mempengaruhi pembelian. Menurut Levy \& Weitz (2004 : 521 ) pengaruh store atmosphere merupakan kombinasi dari karakteristik fisik toko seperti arsitektur, tata letak, pemajangan warna, pencahayaan, sirkulasi udara, musik serta aroma yang secara menyeluruh akan menciptakan cifra dalam benak konsumen.

Hasil penelitian yang dilakukan oleh Yistiani dkk. (2012) menunjukkan bahwa store atmosphere berpengaruh positif dan signifikan terhadap pembelian impulsif dimana semakin baik gerai yang diciptakan akan dapat mendorong terjadinya pembelian impulsif. Menurut hasil penelitian dari Tendai \& Crispen (2009), Kurniawan (2013), Sari (2014) menunjukkan bahwa store atmosphere berpengaruh positif dan signifikan terhadap pembelian impulsif. Berdasarkan pemaparan di atas, maka diajukan hipotesis pertama yaitu:

$\mathrm{H}_{1}$ : Atmosfer ritel berpengaruh positif dan signifikan terhadap Impulse Buying

Impulse buying memainkan peran penting bagi pengusaha untuk mencapai tujuan promosi perusahaan (Muruganantham dan Bhakat, 2013). Tujuan dari promosi adalah untuk meningkatkan volume penjualan jangka pendek dengan 
menciptakan aktivitas - aktivitas promosi penjualan yang tepat untuk medorong impulse buying. Seorang tenaga penjualan terlatih dapat menurunkan frustrasi dengan membimbing dan membantu konsumen dalam proses pembelian dan mengaktifkan perilaku impulse buying (Iqbal et al., 2014). Promosi yang paling mempengaruhi konsumen adalah masalah harga, pengaruh positif promosi penurunan harga dapat meningkatkan pemikiran untuk membeli barang oleh konsumen (Vishnu dan Raheem, 2013). Perilaku konsumen saat ini telah berubah menjadi lebih hemat, dimana konsumen menginginkan penekanan nilai lebih besar dan meningkatkan fokus pada kenyamanan (Rittipant et al., 2013).

Berdasarkan hasil penelitian dari Kumiawan dan Kunto (2013), promosi berpengaruh positif dan signifikan pada Impulse Buying. Penelitian yang dilakukan oleh Sari dan Suryani (2014), Putra (2014) juga menyatakan bahwa semakin baik kegiatan promosi yang dilakukan akan meningkatkan pembelian impulsif. Berdasarkan pemaparan di atas, maka diajukan hipotesis kedua yaitu:

$\mathrm{H}_{2}$ : Promosi berpengaruh positif dan signifikan terhadap Impulse Buying.

Pada dasarnya tingkah laku manusia dipengaruhi oleh lingkungan sekitamya. Penciptaan Atmosfer ritel yang baik akan dirasa nyaman oleh konsumen sehingga dapat berpengaruh secara langsung pada emosional konsumen saat berada di dalam gerai. Atmosfer ritel yang dirancang dengan baik dan sesuai dengan target pasar yang ditetapkan akan mampu menciptakan emosi positif konsumen saat berbelanja (Sinaga dkk., 2012).

Penelitian Chang dan Yan (2009) juga menunjukkan bahwa stimulus yang ditimbulkan oleh lingkungan toko berpengaruh positif dan terhadap respon emosi 
A A Bagus Jambe Negara dan Ni Made Wulandari Kusumadewi, Pengaruh Atmosfer.....

positif konsumen. Didukung juga oleh hasil penelitian Madjid (2014), Margana dan Setiawan (2014), Kurniawati dan Restuti (2014), Hetharie (2011) bahwa Store Atmosphere memiliki pengaruh positif dan signifikan terhadap Shopping Emotion. Berdasarkan pemaparan di atas, maka diajukan hipotesis ketiga yaitu:

$\mathrm{H}_{3}$ : Atmosfer ritel berpengaruh positif dan signifikan terhadap Emosi Positif.

Promosi adalah suatu komunikasi informasi penjual dan pembeli yang bertujuan untuk merubah sikap dan tingkah laku pembeli, yang sebelumnya tidak mengenal menjadi mengenal sehingga menjadi membeli dan mengingat produk tersebut (Fahd, 2015).

Berdasarkan hasil penelitian dari Kumiawan dan Kunto (2013), promosi berpengaruh positif dan signifikan pada Emosi Positif. Menurut hasil penelitian Kumiawati dan Restuti (2014) promosi memiliki pengaruh yang positif dan signifikan terhadap Emosi Positif. Berdasarkan pemaparan di atas, maka diajukan hipotesis keempat yaitu:

$\mathrm{H}_{4}$ : Promosi berpengaruh positif dan signifikan terhadap Emosi Positif.

Faktor lain yang dapat berpengaruh pada seseorang saat terlibat dalam pola perilaku pembelian impulsif adalah emosi positif (Rachmawati, 2009). Emosi positif dapat ditimbulkan melalui sifat afektif seseorang dan reaksi pada lingkungan yang mendukung seperti ketertarikan pada suatu produk (Rachmawati.,2009). Pattipeilohy (2013) menyatakan bahwa mood seseorang yang sudah ada sebelumnya, sifat afektif, dan respon terhadap lingkungan dapat menumbuhkan emosi positif. Penciptaan emosi positif pada konsumen mengenai suatu produk atau bahkan lingkungan toko dapat meningkatkan motif konsumen 
dalam melakukan pembelian impulsif (Amiri et al., 2012).

Penelitan yang dilakukan oleh Hetharie (2011) yang menyatakan emosi positif yang dirasakan oleh konsumen pada waktu berbelanja mempengaruhi keputusan pembelian impulsif . Penelitian ini juga sejalan dengan penelitian yang dilakukan oleh Margana dan Setiawan (2014), Budiharta (2015), Anggoro (2013), Marianty (2014) dan Nasir (2010) yang menyatakan bahwa emosi positif berpengaruh positif dan signifikan terhadap pembelian impulsif. Berdasarkan pemaparan di atas, maka diajukan hipotesis kelima yaitu :

$\mathrm{H}_{5}$ : Emosi positif berpengaruh positif dan signifikan terhadap Impulse Buying.

Penelitian Adelaar (2003) menyatakan bahwa store atmosphere berpengaruh positif dan signifikan terhadap pembelian impulsif yang dimediasi oleh emosi positif. Peran Atmosfer ritel dalam gerai ritel dapat memberi perasaan nyaman kepada konsumen yang nantinya berdampak pada emosi yang dirasakan sehingga mampu memperpanjang waktu konsumen berada di dalam gerai dan probabilitas konsumen untuk melakukan pembelian impulsif tentunya akan semakin besar.

Penelitian yang di lakukan oleh Hetharie (2011) yang menyatakan bahwa emosi positif menghasilkan pengaruh positif sebagai variabel intervening antara pengaruh atmosfer gerai terhadap impulse buying. Hasil penelitian tersebut didukung oleh penelitian Margana (2014) menyatakan bahwa pembelian impulsif dipengaruhi oleh stimulus lingkungan toko dan faktor sosial toko yang dimediasi oleh emosi positif yang dirasakan konsumen. Berdasarkan pemaparan di atas, maka diajukan hipotesis keenam yaitu:

$\mathrm{H}_{6}$ : Emosi positif memediasi atmosfer ritel terhadap Impulse Buying 
A A Bagus Jambe Negara dan Ni Made Wulandari Kusumadewi, Pengaruh Atmosfer.....

Atmosfer ritel mempengaruhi keadaan emosi pembeli yang menyebabkan atau mempengaruhi pembelian. Keadaan emosional akan membuat dua perasaan yang dominan yaitu perasaan senang dan membangkitkan keinginan (Kumiawan dan Kunto, 2013). Suasana gerai direncanakan sesuai dengan pasar sasarannya dan dapat menarik konsumen untuk melakukan pembelian (Kotler, 2005). Adanya Atmosfer ritel yang menarik minat konsumen akan meningkatkan emosi, hal tersebut akan memicu timbulnya impulse buying.

Hasil penelitian Madjid (2014) bahwa atmosfer ritel memiliki pengaruh positif dan signifikan terhadap emosi positif. Penelitian yang di lakukan oleh Kurniawan dan Kunto (2013) yang menyatakan bahwa promosi menghasilkan pengaruh positif sebagai variabel intervening antara pengaruh promosi terhadap pembelian impulsif. Berdasarkan pemaparan di atas, maka diajukan hipotesis ketujuh yaitu:

$\mathrm{H}_{7}$ : Emosi positif memediasi promosi terhadap Impulse Buying

\section{METODE PENELITIAN}

Penelitian ini ialah penelitian asosiatif yang menguji hubungan variabel yaitu Atmosfer ritel terhadap impulse buying, pengaruh promosi terhadap impulse buying, pengaruh variabel atmosfer ritel terhadap emosi posiff, pengaruh variable promosi terhadap emosi positif, variabel emosi positif terhadap impulse buying, serta peran emosi positif dalam memediasi atmosfer ritel terhadap impulse buying, dan peran emosi positif dalam memediasi promosi terhadap impulse buying konsumen Carrefour Hypermart. 
Lokasi penelitian dilakukan di Hypermart Carrefour Denpasar yang beralamat di Jalan Sunset Road Denpasar. Alasan pemilihan lokasi penelitian tersebut karena Hypermart Carrefour merupakan salah satu tempat perbelanjaan modern yang menyediakan beraneka ragam barang dagangan dan masih tetap eksis dan lokasinya mudah dijangkau oleh konsumen. Sedangkan objek penelitiannya adalah Pengaruh Atmosfer Ritel dan Promosi terhadap Emosi Positif dan Impulse Buying di Hypermarket Carrefour Denpasar.

Pada penelitian ini, variabel penelitian dan indikator variabel penelitian disajikan pada Tabel 1 .

Tabel 1.

Indikator Penelitian

\begin{tabular}{|c|c|c|}
\hline Variabel & Indikator & Referensi \\
\hline $\begin{array}{l}\text { Impulse } \\
\text { Buying }\end{array}$ & $\begin{array}{l}\text { 1. Pembelian tidak direncanakan } \\
\text { 2. Pembelian dengan model terbaru } \\
\text { 3. Pembelian walau tidak sesuai keinginan }\end{array}$ & $\begin{array}{l}\text { Putra (2014), } \\
\text { Kurniawan dan Kunto } \\
\qquad(2013)\end{array}$ \\
\hline Promosi & $\begin{array}{l}\text { 1. Member card } \\
\text { 2. Cash back } \\
\text { 3. Buy } 2 \text { get } 1 \\
\text { 4. Hadiah langsung }\end{array}$ & $\begin{array}{l}\text { Kurniawan dan Kunto } \\
\text { (2013),putra(2014) dan } \\
\text { Nasir (2010) }\end{array}$ \\
\hline Atmosfer Ritel & $\begin{array}{l}\text { 1. Penataan cahaya } \\
\text { 2. Aroma } \\
\text { 3. Dekorasi } \\
\text { 4. Musik } \\
\text { 5. Tata ruang dan letak }\end{array}$ & $\begin{array}{l}\text { Muruganatham \& Ravi } \\
\text { (2013), Yistiani dkk. } \\
\text { (2012), Ma'ruf } \\
\text { (2006:204) }\end{array}$ \\
\hline Emosi Positif & $\begin{array}{l}\text { 1. Senang } \\
\text { 2. Nyaman } \\
\text { 3. Antusias } \\
\text { 4. Puas }\end{array}$ & $\begin{array}{l}\text { Kumiawan (2013), } \\
\text { Rachmawati (2009) }\end{array}$ \\
\hline
\end{tabular}

Sumber : Cakraningrat 2016 dan diubah sesuai kebutuhan penelitian.

Jenis data yang digunakan dalam penelitian ini adalah data kuantitatif berupa jumlah responden penelitian. Data kualitatif berupa hasil kuesioner dari 
A A Bagus Jambe Negara dan Ni Made Wulandari Kusumadewi, Pengaruh Atmosfer.....

responden. Sedangkan sumber data yang digunakan dalam penelitian ini adalah sumber primer diperoleh dari jawaban responden terhadap kuisioner tentang variabel penelitian yang akan diuji. Sumber sekunder diperoleh dari Hypermarket Carrefour Denpasar mengenai gambaran umum data juga diambil dari beritaberita online, dan studi empiris yang berkaitan dengan variabel atmosfer ritel, promosi, emosi positif, dan impulse buying.

Populasi dalam penelitian ini adalah seluruh konsumen yang pemah berbelanja di Hypermarket Carrefour Denpasar dan pernah melakukan impulse buying. Pengumpulan sampel menggunakan teknik purposive sampling. Jumlah indikator dalam penelitian ini adalah 16 buah sehingga didapat jumlah sampel yang digunakan sebanyak 112 sampel (16x7).

Metode pengumpulan data yang digunakan dalam penelitian ini adalah metode wawancara langsung dengan menggunakan alat bantu kuesioner kepada responden untuk memperoleh data yang dibutuhkan. Proses wawancara akan dilakukan terhadap responden yang pernah melakukan pembelian di Hypermarket Carrefour Denpasar.

Penelitian ini menggukanan teknik analisis jalur (path analysis). Pengaruh atmosfer ritel (X1) terhadap emosi positif (Y) ditunjukkan oleh koefisien jalur $\beta 1$, pengaruh promosi (X2) terhadap emosi positif (Y) ditunjukkan oleh koefisien jalur $\beta 2$, pengaruh langsung atmosfer ritel (X1) terhadap impulse buying (M) diperlihatkan oleh koefisien jalur $\beta 3$, pengaruh langsung promosi (X2) terhadap impulse buying (M) diperlihatkan oleh koefisien jalur $\beta 4$ dan pengaruh emosi positif (Y) terhadap impulse buying (M) diperlihatkan oleh koefisien jalur $\beta 4$. 


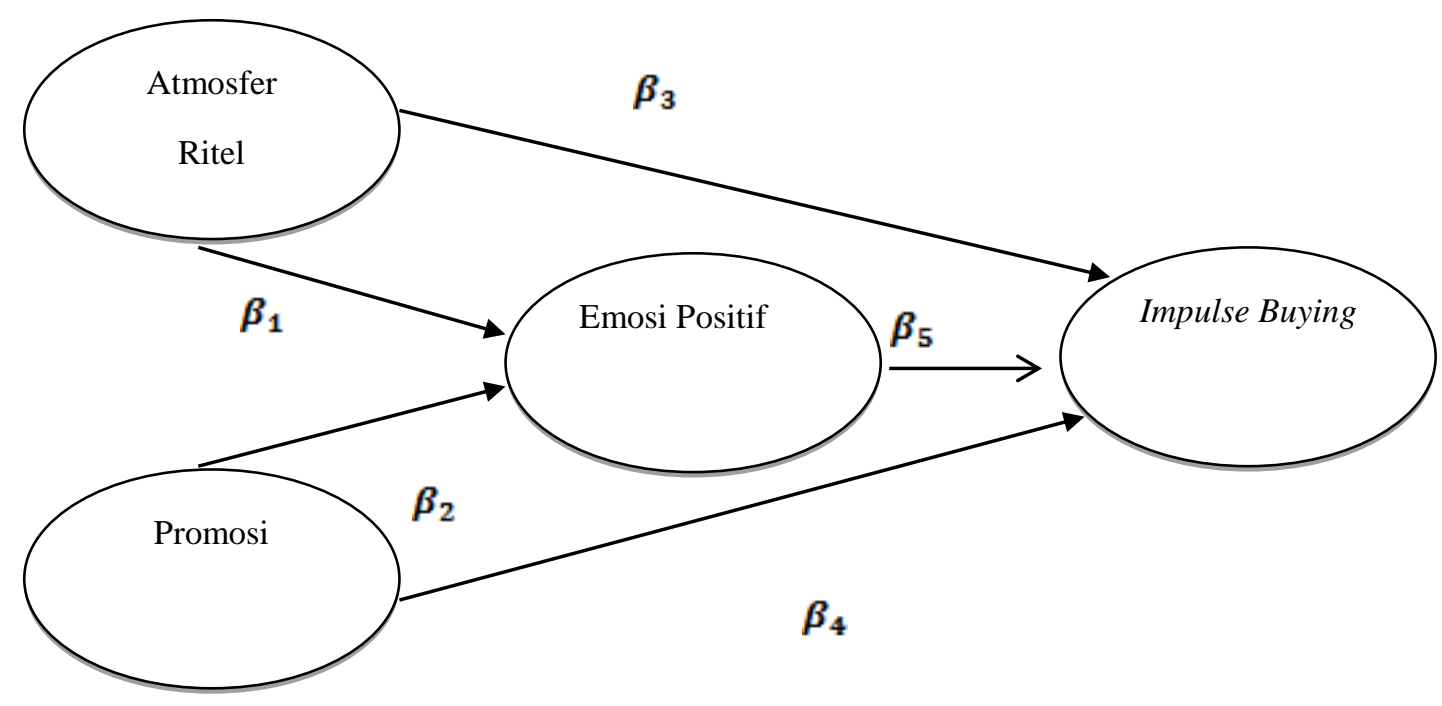

\section{Gambar 1. Diagram Jalur Penelitian}

Koefisien jalur dapat diperoleh dengan dua persamaan struktural, yaitu persamaan regresi yang menunjukkan hubungan yang telah dihipotesiskan. Dua persamaan struktural tersebut ialah:

$$
\begin{aligned}
& \mathrm{Y}_{1}=\beta_{1} x_{1}+\beta_{2} x_{2}+\varepsilon_{1} \\
& Y_{2}=\beta_{3} x_{1}+\beta_{4} x_{2}+\beta_{5} y_{1}+\varepsilon_{2}
\end{aligned}
$$

\section{Uji Mediasi (Uji Sobel)}

Uji Sobel digunakan dengan menguji kekuatan pengaruh tidak langsung variabel Atmosfer Ritel $\left(\mathrm{X}_{1}\right)$ terhadap variabel Impulse Buying $\left(\mathrm{Y}_{2}\right)$ melalui variabel Emosi Positif $\left(\mathrm{Y}_{1}\right)$ dan Promosi $\left(\mathrm{X}_{2}\right)$ terhadap variabel Impulse Buying $\left(\mathrm{Y}_{2}\right)$ melalui variabel Emosi Positif $\left(\mathrm{Y}_{1}\right)$. Berdasarkan diagram jalur pengaruh tidak langsung, maka dapat dihitung standar error koefisien a dan b ditulis dengan 
A A Bagus Jambe Negara dan Ni Made Wulandari Kusumadewi, Pengaruh Atmosfer.....

$\mathrm{S}_{\mathrm{a}}$ dan $\mathrm{S}_{\mathrm{b}}$, besarnya standar error tidak langsung (indirect effect) $\mathrm{S}_{\mathrm{ab}}$ dihitung dengan rumus berikut ini:

$$
\mathrm{S}_{\mathrm{ab}}=\sqrt{b^{2} S_{a}^{2}+a^{2} S_{b}^{2}+S_{a}^{2} S_{b}^{2}}
$$

Apabila hasil nilai perhitungan $Z>1,96$ (tingkat kepercayaan 95 persen), maka variabel intervening dianggap secara signifikan memediasi hubungan antara variabel eksogen dan variabel endogen.

\section{HASIL DAN PEMBAHASAN}

\section{Karakteristik Responden}

Karakteristik responden penelitian mengenai pengaruh atmosfer ritel dan promosi terhadap impulse buying yang dimediasi emosi positif pada Hypermart Carrefour Denpasar dapat dilihat dari beberapa kriteria yaitu: jenis kelamin, umur, pendidikan terakhir,dan jenis pekerjaan. Berikut disajikan karakteristik responden dari berbagai kriteria tersebut.

Tabel 2. menunjukkan jumlah responden berjenis kelamin perempuan sebanyak 62 orang $(55,36$ persen), dan jumlah responden berjenis kelamin lakilaki sebanyak 50 orang (44,64 persen). Hal ini menunjukan bahwa konsumen yang pernah berbelanja di Hypermarket Carrefour Denpasar di dominasi oleh responden berjenis kelamin perempuan.

Berdasarkan umur responden dapat diketahui bahwa jumlah responden yang berumur 27-36 tahun sebanyak 46 orang (41,07 persen), jumlah responden yang berumur 17-26 tahun sebanyak 27 orang (24,11 persen), jumlah responden yang berumur 37-46 tahun sebanyak 18 orang (16,07 persen), jumlah responden yang 
berumur 47-56 tahun sebanyak 16 orang (14,28 persen) dan jumlah responden yang berumur $>56$ tahun sebanyak 5 orang $(4,46$ persen). Hal ini menunjukan bahwa konsumen yang pernah berbelanja di Hypermarket Carrefour di dominasi oleh responden yang berusia 27-36 tahun.

Tabel 2.

Karakteristik Responden

\begin{tabular}{|c|c|c|c|c|}
\hline No & Variabel & Klasifikasi & Jumlah & Persentase (\%) \\
\hline \multirow[t]{2}{*}{1} & Jenis Kelamin & Laki-laki & 50 & 44,64 \\
\hline & & Perempuan & 62 & 55,36 \\
\hline & Jumlah & & 112 & 100 \\
\hline \multirow[t]{6}{*}{2} & Usia & $17-26$ Tahun & 27 & 24,11 \\
\hline & & $27-36$ Tahun & 46 & 41,07 \\
\hline & & 37 - 46 Tahun & 18 & 16,07 \\
\hline & & $47-56$ Tahun & 16 & 14,28 \\
\hline & & $>56$ Tahun & 5 & 4,46 \\
\hline & Jumlah & & 112 & 100 \\
\hline \multirow[t]{5}{*}{3} & Pendidikan & SMA & 22 & 19,64 \\
\hline & & Diploma & 30 & 26,78 \\
\hline & & $\begin{array}{c}\text { Sarjana/Pasca } \\
\text { Sarjana }\end{array}$ & 58 & 51,78 \\
\hline & & Lainnya & 2 & 1,78 \\
\hline & Jumlah & & 112 & 100 \\
\hline \multirow[t]{7}{*}{4} & Jenis Pekerjaan & Pelajar & 11 & 9,82 \\
\hline & & Pegawai Swasta & 40 & 35,71 \\
\hline & & Mahasiswa & 12 & 10,71 \\
\hline & & Wiraswasta & 21 & 18,75 \\
\hline & & PNS & 25 & 22,32 \\
\hline & & Lainnya & 3 & 2,68 \\
\hline & Jumlah & & 112 & 100 \\
\hline
\end{tabular}

Sumber: Data primer, data diolah, 2017

Berdasarkan pendidikan terakhir Sarjana/Pasca Sarjana sebanyak 58 orang (51,78 persen), responden berdasarkan pendidikan terakhir Diploma sebanyak 30 orang (26,78 persen), responden berdasarkan pendidikan terakhir SMA sebanyak 22 orang (19,64 persen), dan responden dengan pendidikan lainnya sebanyak 2 orang (1,78 persen). Seseorang yang memiliki tingkat pendidikan Sarjana/Pasca Sarjana diasumsikan memiliki pemahaman dan kemampuan dalam pengelolaan 
A A Bagus Jambe Negara dan Ni Made Wulandari Kusumadewi, Pengaruh Atmosfer.....

dana sehingga mampu mengatur maupun menggunakan pendapatannya untuk berbelanja di Hypermarket Carrefour Denpasar. Berdasarkan jenis pekerjaan sebagian besar responden yang pernah berbelanja di Hypermarket Carrefour Denpasar memiliki status pekerjaan sebagai pegawai swasta dengan jumlah responden sebanyak 40 orang (35,71 persen), kemudian diiukuti dengan responden yang bekerja sebagai PNS sebanyak 25 orang (22,32 persen). Responden yang bekerja sebagai Wiraswasta sebanyak 21 orang (18,75 persen). Responden yang merupakan mahasiswa sebanyak 12 orang (10,71 persen). Responden yang merupakan pelajar sebanyak 11 orang $(9,82$ persen $)$ dan responden lainnya sebanyak 3 orang (2,68 persen). Pekerjaan sebagai pegawai swasta maupun PNS pada umumnya memiliki jumlah penghasilan yang tetap, sehingga dengan penghasilan tersebut seseorang sudah mampu untuk mengelola maupun menggunakan pendapatannya untuk berbelanja maupun melakukan pembelian tidak terencana di Hypermarket Carrefour Denpasar.

\section{Hasil Uji Validitas}

Uji validitas bertujuan untuk mengukur pertanyaan-pertanyaan kuesioner yang harus dibuang atau diganti karena dianggap tidak relevan. Item instrumen dianggap valid jika lebih $\geq 0,3$. Berikut adalah hasil uji validitas.

Hasil uji validitas pada tabel 3. menunjukkan bahwa seluruh instrumen penelitian yang digunakan untuk mengukur variabel atmosfer ritel, promosi, emosi positif dan impulse buying memiliki nilai koefisien korelasi dengan skor total seluruh item pernyataan lebih besar dari 0,30 dengan signifikansi kurang dari 
0,05. Hal ini menunjukkan bahwa butir-butir pernyataan dalam instrument penelitian tersebut valid dan layak digunakan sebagai instrument penelitian.

Tabel 3.

Hasil Uji Validitas Instrumen Penelitian

\begin{tabular}{ccccc}
\hline Variabel & Indikator & Koefisien Korelasi & Sig. (2-tailed) & Keterangan \\
\hline & $\mathrm{X}_{1.1}$ & 0,781 & 0,000 & Valid \\
& $\mathrm{X}_{1.2}$ & 0,829 & 0,000 & Valid \\
Atmosfer Ritel $\left(\mathrm{X}_{1}\right)$ & $\mathrm{X}_{1.3}$ & 0,782 & 0,000 & Valid \\
& $\mathrm{X}_{1.4}$ & 0,756 & 0,000 & Valid \\
& $\mathrm{X}_{1.5}$ & 0,893 & 0,000 & Valid \\
& $\mathrm{X}_{2.1}$ & 0,837 & 0,000 & Valid \\
\multirow{5}{*}{ Promosi $\left(\mathrm{X}_{2}\right)$} & $\mathrm{X}_{2.2}$ & 0,881 & 0,000 & Valid \\
& $\mathrm{X}_{2.3}$ & 0,836 & 0,000 & Valid \\
& $\mathrm{X}_{2.4}$ & 0,861 & 0,000 & Valid \\
& $\mathrm{Y}_{1.1}$ & 0,860 & 0,000 & Valid \\
Emosi Positif $\left(\mathrm{Y}_{1}\right)$ & $\mathrm{Y}_{1.2}$ & 0,829 & 0,000 & Valid \\
& $\mathrm{Y}_{1.3}$ & 0,918 & 0,000 & Valid \\
& $\mathrm{Y}_{1.4}$ & 0,880 & 0,000 & Valid \\
& $\mathrm{Y}_{2.1}$ & 0,926 & 0,000 & Valid \\
Impulse Buying $\left(\mathrm{Y}_{2}\right)$ & $\mathrm{Y}_{2.2}$ & 0,905 & 0,000 & Valid \\
& $\mathrm{Y}_{2.3}$ & 0,944 & 0,000 & Valid \\
\hline
\end{tabular}

Sumber: Data primer diolah, 2017

\section{Hasil Uji Reliabilitas}

Uji reliabilitas mampu menunjukan sejauh mana instrument dapat dipercaya dan diharapkan. Nilai suatu instrument dikatakan reliable apabila nilai Alpha Cronbach $\geq 0,6$. Hasil uji reliabilitas dapat dilihat pada Tabel 4. berikut.

Tabel 4. Hasil Uji Reliabilitas Instrumen Penelitian

\begin{tabular}{clcc}
\hline No. & \multicolumn{1}{c}{ Variabel } & Cronbach's Alpha & Keterangan \\
\hline 1 & Atmosfer Ritel $\left(\mathrm{X}_{1}\right)$ & 0,866 & Reliabel \\
2 & Promosi $\left(\mathrm{X}_{2}\right)$ & 0,871 & Reliabel \\
3 & Emosi Positif $\left(\mathrm{Y}_{1}\right)$ & 0,884 & Reliabel \\
4 & Impulse Buying $\left(\mathrm{Y}_{2}\right)$ & 0,914 & Reliabel \\
\hline Sumber: & Data primer diolah, 2017
\end{tabular}

Hasil uji reliabilitas yang disajikan dalam Tabel 4. menunjukkan bahwa seluruh instrumen penelitian memiliki koefisien Cronbach's Alpha lebih dari 
A A Bagus Jambe Negara dan Ni Made Wulandari Kusumadewi, Pengaruh Atmosfer.....

0,60. Jadi dapat dinyatakan bahwa seluruh variabel telah memenuhi syarat reliabilitas atau sehingga dapat digunakan untuk melakukan penelitian.

\section{Hasil Analisis Faktor Konfirmatori}

Uji Kaiser Meyer Olkin digunakan untuk mengetahui kecukupan sampel. Analisis faktor dianggap layak jika besaran KMO memiliki nilai minimal 0,5. Hasil uji KMO dapat dilihat pada Tabel 5.

Tabel 5.

\section{Hasil Uji KMO}

\begin{tabular}{cll}
\hline No & \multicolumn{1}{c}{ Variabel } & KMO \\
\hline 1 & Atmosfer Ritel $\left(\mathrm{X}_{1}\right)$ & 0,839 \\
2 & Promosi $\left(\mathrm{X}_{2}\right)$ & 0,757 \\
3 & Emosi Positif $\left(\mathrm{Y}_{1}\right)$ & 0,789 \\
4 & Impulse Buying $\left(\mathrm{Y}_{2}\right)$ & 0,727 \\
\hline Sumber: & Data primer diolah, 2017
\end{tabular}

Hasil uji yang ditunjukkan Tabel 5. memperlihatkan semua variabel memiliki $\mathrm{KMO}>$ 0,5. Hal ini menyimpulkan bahwa masing-masing variabel memiliki kecukupan sampel untuk analisis faktor.

Kelayakan model uji faktor untuk masing-masing variabel dapat dilihat dari nilai Measures of Sampling Adequancy (MSA). Nilai MSA yang diperoleh dari masing-masing variabel besar dari 0,5 . Hal ini berarti masing-masing model layak digunakan dalam analisis faktor.

Hasil Percentage of Variance menjelaskan kemampuan dari masing-masing faktor untuk menjelaskan variasinya. Data nilai Percentage of Variance dapat dilihat pada Tabel 6.. Pada Tabel 6. nilai Persentage of Variance masing-masing variabel sudah lebih besar dari 60 persen. Hal ini berarti faktor dari masingmasing variabel memiliki kelayakan untuk menjelaskan variabel faktornya. 
Tabel 6.

Nilai Percentage of Variance

\begin{tabular}{ccc}
\hline No & Variabel & Persentage of Variance \\
\hline 1 & Atmosfer Ritel $\left(\mathrm{X}_{1}\right)$ & 69,345 \\
2 & Promosi $\left(\mathrm{X}_{2}\right)$ & 73,349 \\
& Emosi Positif $\left(\mathrm{Y}_{1}\right)$ & 73,936 \\
3 & Impulse Buying $\left(\mathrm{Y}_{2}\right)$ & 80,296 \\
\hline
\end{tabular}

Sumber: Data primer diolah, 2017

Kelayakan model uji faktor untuk masing-masing variabel juga dapat dilihat dari nilai Loading Factor. Nilai Loading Factor yang diperoleh dari masingmasing variabel dapat dilihat pada Tabel 7.

Tabel 7.

Loading Factor

\begin{tabular}{cccccccc}
\hline \multicolumn{2}{c}{ Atmosfer Ritel $\left(\mathrm{X}_{1}\right)$} & \multicolumn{2}{c}{ Promosi $\left(\mathrm{X}_{2}\right)$} & \multicolumn{2}{c}{ Emosi Positif $\left(\mathrm{Y}_{1}\right)$} & \multicolumn{2}{c}{ Impulse Buying $\left(\mathrm{Y}_{2}\right)$} \\
Indikator & $\begin{array}{c}\text { Factor } \\
\text { Loading }\end{array}$ & Indikator & $\begin{array}{c}\text { Factor } \\
\text { Loading }\end{array}$ & Indikator & $\begin{array}{c}\text { Factor } \\
\text { Loading }\end{array}$ & Indikator & $\begin{array}{c}\text { Factor } \\
\text { Loading }\end{array}$ \\
\hline $\mathrm{X}_{1.1}$ & 0,801 & $\mathrm{X}_{2.1}$ & 0,856 & $\mathrm{Y}_{1.1}$ & 0,855 & $\mathrm{Y}_{2.1}$ & 0,890 \\
$\mathrm{X}_{1.2}$ & 0,848 & $\mathrm{X}_{2.2}$ & 0,834 & $\mathrm{Y}_{1.2}$ & 0,809 & $\mathrm{Y}_{2.2}$ & 0,877 \\
$\mathrm{X}_{1.3}$ & 0,821 & $\mathrm{X}_{2.3}$ & 0,856 & $\mathrm{Y}_{1.3}$ & 0,906 & $\mathrm{Y}_{2.3}$ & 0,921 \\
$\mathrm{X}_{1.4}$ & 0,822 & $\mathrm{X}_{2.4}$ & 0,880 & $\mathrm{Y}_{1.4}$ & 0,867 & & \\
$\mathrm{X}_{1.5}$ & 0,870 & & & & & & \\
\hline \multicolumn{2}{l}{ Sumber: Data primer diolah, 2017}
\end{tabular}

Hasil analisis faktor konfirmatori menunjukan semua indikator konstruk tersebut mempunyai loading faktor dengan nilai diatas 0,5 . Hal ini menunjukkan variabel tersebut sebagai indikator yang kuat.

\section{Hasil Analisis Jalur}

Berdasarkan hasil perhitungan koefisien regresi, nilai error dan determinasi total, maka dapat disusun diagram model analisis jalur seperti pada gambar 2 . sebagai berikut 


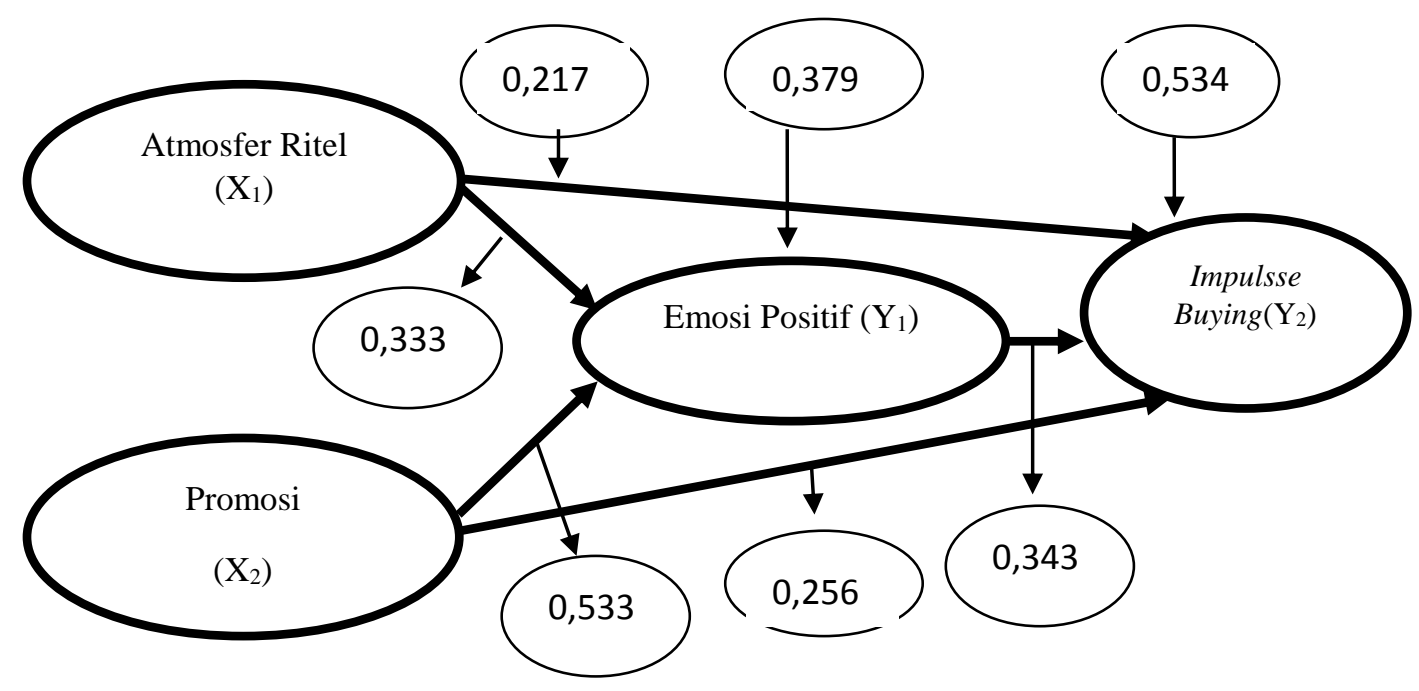

Gambar 2. Model Diagram Jalur Akhir

Berdasarkan diagram jalur pada Gambar 2., maka dapat dihitung besarnya pengaruh langsung dan pengaruh tidak langsung serta pengaruh total antar variabel. Perhitungan pengaruh antar variabel dirangkum dalam Tabel 8. sebagai berikut.

Tabel 8.

Pengaruh Langsung dan Pengaruh Tidak Langsung serta Pengaruh Total Analisis Jalur Variabel Penelitian

\begin{tabular}{cccc}
\hline $\begin{array}{c}\text { Pengaruh } \\
\text { Variabel }\end{array}$ & $\begin{array}{c}\text { Pengaruh } \\
\text { Langsung }\end{array}$ & $\begin{array}{c}\text { Pengaruh Tidak Langsung Melalui } \\
\text { Emosi Positif } \\
(\mathbf{Y 1})(\boldsymbol{\beta} 1 \mathbf{x} \boldsymbol{\beta 3})\end{array}$ & Pengaruh Total \\
\hline $\mathrm{X}_{1} \rightarrow \mathrm{Y}_{1}$ & 0,333 & - & 0,333 \\
$\mathrm{X}_{1} \rightarrow \mathrm{Y}_{2}$ & 0,217 & 0,114 & 0,331 \\
$\mathrm{Y}_{1} \rightarrow \mathrm{Y}_{2}$ & 0,343 & - & 0,343 \\
$\mathrm{X}_{2} \rightarrow \mathrm{Y}_{1}$ & 0,533 & - & 0,533 \\
$\mathrm{X}_{2} \rightarrow \mathrm{Y}_{2}$ & 0,256 & 0,183 & 0,439 \\
\hline \multicolumn{2}{l}{ Sumber: Data primer diolah, 2017} & &
\end{tabular}

Nilai determinasi total sebesar0,959 mempunyai arti bahwa sebesar 95,9 persen variasi Impulse Buying dipengaruhi oleh variasi atmosfer ritel, promosi dan 
emosi positif, sedangkan sisanya sebesar 4,1 persen djelaskan oleh faktor lain yang tidak dimasukkan ke dalam model.

\section{Uji Sobel}

Uji sobel digunakan untuk menguji signifikansi variabel emosi positif sebagai variabel mediasi dalam hubungan antara variabel atmosfer ritel dan impulse buying serta hubungan antara variabel promosi dan impulse buying dengan nilai masing-masing $Z=2,266>1,96$ tingkat signifikansi $0.023<0.05$ dan 2,399 > 1,96 tingkat signifikansi $0.016<0.05$ berarti variabel mediator emosi positif dinilai secara signifikan memediasi pengaruh atmosfer ritel terhadap impulse buying dan memediasi pengaruh promosi terhadap impulse buying.

\section{Pengaruh Atmosfer Ritel Terhadap Impulse Buying}

Atmosfer ritel adalah perubahan yang dibuat pada desain dari lingkungan membeli yang menghasilkan efek emosional khusus yang kemudian meningkatkan kemungkinan bahwa pembelian akan berlangsung. Keadaan emosi konsumen dipengaruhi Store Atmosphere yang menyebabkan atau mempengaruhi pembelian (Gilbert, 2003:129). Hasil pengujian menemukan pengaruh positif dari variabel atmosfer ritel terhadap impulse buying yang artinya $\mathrm{H}_{1}$ diterima. Hasil penelitian sesuai dengan penelitian sebelumnya oleh Muruganatham \& Ravi (2013) yang menyatakan bahwa salah satu faktor yang mendorong teiadinya pembelian impulsif adalah store atmosphere. Hasil serupa yang diperoleh Yistiani dkk. (2012), Tendai dan Crispen (2009), dan Kurniawan (2013) juga menunjukkan bahwa store atmosphere berpengaruh positif dan signifikan terhadap pembelian impulsif dimana semakin baik gerai yang 
A A Bagus Jambe Negara dan Ni Made Wulandari Kusumadewi, Pengaruh Atmosfer.....

diciptakan akan dapat mendorong terjadinya pembelian impulsif. Berdasarkan hasil tersebut ditemukan implikasi bahwa atmosfer ritel berpengaruh positif dan signifikan terhadap perilaku pembelian tidak terencana konsumen Hypermart Carrefour Denpasar. Atmosfer ritel yang terdiri dari penataan cahaya, aroma ruangan, desain ruangan yang bagus, musik yang diputar enak didengar dan tata letak rak yang membuat ruang terasa luas mampu mempengaruhi perilaku pembelian tidak terencana konsumen. Semakin nyaman konsumen merasakan atmosfer ritel pada Hypermart Carrefour Denpasar, maka akan berpotensi meningkatkan impulse buying.

\section{Pengaruh Promosi Terhadap Impulse Buying}

Impulse Buying adalah perilaku berbelanja yang terjadi secara tidak terencana, tertarik secara emosional, di mana proses pembuatan keputusan dilakukan dengan cepat tanpa berpikir secara bijak dan pertimbangan terhadap keseluruhan informasi dan alternatif yang ada (Yistiani, 2012). Berdasarkan hasil pengujian pada hipotesis, ditemukan pengaruh yang positif antara variabel promosi terhadap Impulse Buying yang artinya $\mathrm{H}_{2}$ diterima. Hasil penelitian ini didukung oleh penelitian yang dilakukanoleh Kumiawan dan Kunto (2013) yang menemukan hasil bahwa promosi berpengaruh positif dan signifikan pada Impulse Buying. Penelitian serupa yang dilakukan oleh Sari dan Suryani (2014) serta Putra (2014) juga menemukan hasil bahwa Semakin tinggi tingkat promosi maka akan semakin tinggi juga keputusan impulse buying. Berdasarkan hasil tersebut ditemukan implikasi bahwa promosi berpengaruh positif dan signifikan terhadap perilaku pembelian tidak terencana konsumen Hypermart Carrefour Denpasar. 
Hal ini berarti bahwasemakin menarik promosi yang ditawarkan Hypermart Carrefour Denpasar kepada konsumen, maka perilaku pembelian yang tidak direncanakan pada Hypermart Carrefour Denpasar akan semakin meningkat.

\section{Pengaruh Atmosfer Ritel Terhadap Emosi Positif}

Atmosfer ritel yang dirancang dengan baik dan sesuai dengan target pasar yang ditetapkan akan mampu menciptakan emosi positif konsumen saat berbelanja (Sinaga dkk., 2012). Berdasarkan hasil pengujian pada hipotesis, ditemukan pengaruh yang positif antara variabel atmosfer ritel terhadap emosi positif yang artinya $\mathrm{H}_{3}$ diterima. Hasil penelitian ini didukung oleh penelitian yang dilakukan oleh Kurniawan (2013) dan Kusumawati dkk. (2013) yang menyatakan bahwa store atmosphere berpengaruh positif dan signifikan terhadap emosi positif. Hasil penelitian serupa oleh Kusumawati dkk. (2013), Madjid (2014), Margana dan Setiawan (2014), serta Kurniawati dan Restuti (2014) menyatakan bahwa penciptaan suasana pada lingkungan gerai yang baik akan meningkatkan emosi positif konsumen. Atmosfer ritel berpengaruh positif dan signifikan terhadapemosi positif, memiliki makna bahwaatmosfer gerai yang baik akan membangkitkan perasaan senang, nyaman dan enjoy pada konsumen, maka sikap yang positif terhadap pembelian konsumen pada Hypermart Carrefour Denpasar akan meningkat.

\section{Pengaruh Promosi Terhadap Emosi Positif}

Promosi adalah suatu komunikasi informasi penjual dan pembeli yang bertujuan untuk merubah sikap dan tingkah laku pembeli, yang sebelumnya tidak mengenal menjadi mengenal sehingga menjadi membeli dan mengingat produk 
A A Bagus Jambe Negara dan Ni Made Wulandari Kusumadewi, Pengaruh Atmosfer.....

tersebut (Fahd, 2015). Berdasarkan hasil pengujian pada hipotesis, ditemukan pengaruh yang positif antara variabel Promosi terhadap emosi positifyang artinya $\mathrm{H}_{4}$ diterima. Hasil penelitian ini didukung oleh penelitian yang dilakukanoleh Kumiawan dan Kunto (2013), yang menyatakan bahwa promosi berpengaruh positif dan signifikan pada Emosi Positif. Hasil penelitian serupa oleh Kumiawati dan Restuti (2014) juga memperoleh hasil bahwa promosi memiliki pengaruh yang positif dan signifikan terhadap Emosi Positif. Promosi berpengaruh positif dan signifikan terhadap emosi positif, memiliki makna bahwa promosi yang menarik akan membangkitkan emosi positif pada konsumen untuk melakukan pembelian. Hal ini berarti bahwa semakin menarik promosi yang ditawarkan oleh Hypermart Carrefour Denpasar, maka akan meningkatkan emosi positif konsumen untuk melakukan pembelian di Hypermart Carrefour Denpasar.

\section{Pengaruh Emosi Positif Terhadap Impulse Buying}

Penciptaan emosi positif pada konsumen mengenai satu produk atau artikel atau bahkan lingkungan gerai dapat meningkatkan motif konsumen dalam melakukan impulse buying (Amiri et al., 2012). Seseorang konsumen yang sedang mengalami atau memiliki emosi positif cenderung akan melakukan impulse buying (Putra, 2014). Berdasarkan hasil pengujian pada hipotesis, ditemukan pengaruh yang positif antara variabel emosi positif terhadap impulse buyingyang artinya $\mathrm{H}_{5}$

diterima. Hasil penelitian ini didukung oleh penelitian yang dilakukanoleh Hetharie (2011) yang menyatakan emosi positif yang dirasakan oleh konsumen pada waktu berbelanja mempengaruhi keputusan pembelian impulsif . Penelitian ini juga sejalan dengan penelitian yang dilakukan oleh Margana dan Setiawan 
(2014) yang menyatakan bahwa emosi positif berpengaruh positif dan signifikan terhadap pembelian impulsif. Penelitian serupa yang dilakukan oleh Budiharta (2015), Anggoro (2013), Marianty (2014) dan Nasir (2010) juga memperoleh hasil bahwa emosi positif berpengaruh positif dan signifikan terhadap impulse buying. Emosi positif berpengaruh positif dan signifikan terhadap impulse buying, memiliki makna bahwa semakin positif perasaan konsumen saat melakukan interaksi di dalam gerai, maka kecenderungan konsumen untuk melakukan pembelian impulsif juga semakin besar.

\section{Peran Emosi Positif Memediasi Atmosfer Ritel Terhadap Impulse Buying}

Hasil uji sobel pengaruh tidak langsung variabel atmosfer ritel terhadap variabel impulse buying melalui variabel emosi positif diperoleh nilai $\mathrm{Z}$ sebesar 2,266 lebih besar dari 1,96 dengan tingkat signifikansi $0,023<0,05$ yang berarti variabel mediator yakni emosi positif dinilai secara signifikansi memediasi hubungan antara atmosfer ritel terhadap Impulse Buying. Hasil penelitian ini didukung oleh hasil penelitian yang telah dilakukan oleh Adelaar (2003) yang menyatakan bahwa store atmosphere berpengaruh positif dan signifikan terhadap pembelian impulsif yang dimediasi oleh emosi positif.

Peran Atmosfer ritel dalam gerai ritel dapat memberi perasaan nyaman kepada konsumen yang nantinya berdampak pada emosi yang dirasakan sehingga mampu memperpanjang waktu konsumen berada di dalam gerai dan probabilitas konsumen untuk melakukan pembelian impulsif tentunya akan semakin besar.Penelitian yang di lakukan oleh Hetharie (2011) juga menyatakan bahwa emosi positif menghasilkan pengaruh positif sebagai variabel intervening antara 
A A Bagus Jambe Negara dan Ni Made Wulandari Kusumadewi, Pengaruh Atmosfer.....

pengaruh atmosfer gerai terhadap impulse buying. Hasil penelitian tersebut didukung oleh penelitian Margana (2014) menyatakan bahwa pembelian impulsif dipengaruhi oleh stimulus lingkungan toko dan faktor sosial toko yang dimediasi oleh emosi positif yang dirasakan konsumen. Emosi positif memediasi atmosfer ritel terhadap impulse buying, memiliki makna bahwa konsumen yang merasakan atmosfer ritel yang nyaman pada Hypermart Carrefour Denpasar, lalu didukung dengan adanya emosi positif konsumen berupa perasaan senang dan keinginan untuk membeli, maka akan semakin meningkatkan perilaku pembelian tidak terencana konsumen di Hypermart Carrefour Denpasar.

\section{Peran Emosi Positif Memediasi Promosi Terhadap Impulse Buying}

Hasil uji sobel pengaruh tidak langsung variabel promosi terhadap variabel impulse buying melalui variabel emosi positif diperoleh nilai $\mathrm{Z}$ sebesar 2,399 lebih besar dari 1,96 dengan tingkat signifikansi $0,016<0,05$ yang berarti variabel mediator yakni emosi positif dinilai secara signifikansi memediasi hubungan antara promosi terhadap Impulse Buying. Hasil penelitian ini didukung oleh hasil penelitian yang telah dilakukan oleh Kurniawan dan Kunto (2013) yang menyatakan bahwa emosi positif menghasilkan pengaruh positif sebagai variabel intervening antara pengaruh promosi terhadap pembelian impulsif.

Emosi positif memediasi pengaruh promosi terhadap impulse buying, memiliki makna bahwa adanya penawaran promosi yang menarik dari Hypermart Carrefour Denpasar, lalu didukung dengan adanya emosi positif konsumen berupa perasaan senang dan tertarik untuk melakukan pembelian, dapat semakin 
meningkatkan perilaku pembelian tidak terencana konsumen di Hypermart Carrefour Denpasar.

\section{SIMPULAN DAN SARAN}

Berdasarkan pembahasan hasil penelitian di atas, dapat disimpulkan bahwa Atmosfer ritel berpengaruh positif dan signifikan terhadap impulse buying. Promosi berpengaruh positif dan signifikan terhadap impulse buying. Atmosfer ritel berpengaruh positif dan signifikan terhadap emosi positif konsumen. Promosi berpengaruh positif dan signifikan terhadap emosi positif konsumen. Emosi positif berpengaruh positif dan signifikan terhadap impulse buying. Emosi positif memediasi hubungan antara atmosfer ritel terhadap impulse buying pada konsumen Hypermart Carrefour Denpasar. Emosi positif memediasi hubungan antara promosi terhadap impulse buying pada konsumen Hypermart Carrefour Denpasar. Sementara itu, saran yang dapat diberikan sebaiknya pihak manajemen Hypermart Carrefour Denpasar membuat inovasi tata letak rak dan desain ruangan yang nyaman dan menarik sesuai harapan konsumen, membuat member card yang dapat berfungsi secara efektif dan dapat digunakan sesuai harapan konsumen, membuat inovasi kegiatan bagi konsumen yang berbelanja di Hypermart Carrefour Denpasar, menawarkan produk dengan model terbaru dan selalu menyediakan produk yang dibutuhkan maupun yang diinginkan oleh konsumen. Untuk peneliti selanjutnya, diharapkan melakukan penelitian dengan lokasi, sampel dan responden yang lebih luas. 


\section{DAFTAR RUJUKAN}

Adelaar, T., Chang, S., Lancedorfer, K. M., Lee, B., and Morimoto, M. 2003. Effects of Store Formats on Emotions and Impulse Buying Intent. Journal of Information Technology, Vol.18, pp: 247-266.

Amiri, F., Jalal, J., Mohsen, S., and Tohid, A. 2012. Evaluation of Effective Fashionism Involvement Factors on Impulse Buying of Costumers and Condition of Interrelation between These Factor. Journal of Basic and Applied Scientific Research. 2(9), pp: 9413-9419.

Anggoro, Sandra Puspasari. 2013. Analisis Pengaruh Store Atmosphere Terhadap Impulse Buying melalui Emotional Response di Matahari Department Store Tunjungan Plaza Surabaya. Jurnal Widya Mandala Surabaya, 1(3).

Budiharta Kadek. 2015. Peran Emosi Positif sebagai Pemediasi Pengaruh Stimulus Toko Terhadap Impulse Buying Pakaian di Matahari Department Store Kuta Square. Jurnal Manajamen Universitas Udayana, 4(3), pp : 457-473.

Chang, El., Eckman, M.,and Ym, R. 2009. Impulse Buying Behavior of Apparel: Application of S-O-R Model and Moderating Effect of Hdonic Motivation. ITAA Proceedings.

Chang, Hyo Jung., Yan, Rouh-Nan., Eckan, M. 2013. Moderating Effects ofSituational Characteristics on Impulse Buying.lnternational Journal of Retail \& Distribution Management.Vol. 42 No. 4, pp: 298-314.

Fahd, Faishal. 2015. Analisis Pengaruh Promosi Dan Amosfer Gerai Terhadap Impulse Buying Melalui Emosi Positif Sebagai Variabel Intervening (Studi Pada Toko Busana Muslim Kharisma Banyumanik Semarang). Skripsi Mahasiswa Universitas Diponegoro Fakultas Ekonomika Dan Bisnis.

Graa, Amel, Dani-Elkebir , Maachou, Bensaid, Mohamed. 2014. The Impact of Environmental Factors on Impulse Buying Behavior Using the Mehrabian and Russell's Framework.Leonardo Journal of Sciences.pp: 101-114.

Gilbert, D. 2003. Retail Marketing Management. England: Prentice Hall.

Hetharie, A.J. 2011. Peran Emosi Positif sebagai Mediator Stimulis Lingkungan Toko dan Faktor Sosial Terhadap Impulse Buying Tendency pada Matahari Departement Store Kota Ambon. Jurnal Aplikasi Manajemen 10(4) : 890-898.

Hindarmara, A. /Http://www.frontier.co.id /Research Executive Frontier Consulting. Diunduh tanggal 14, bulan Desember, tahun 2016. 
Iqbal, Anam, Akhtar, Shahzad, Lodhi, Rab Nawaz. 2014. Determinants of Impulsive Buying for Clothing In Pakistan.British Journal of Marketing Studies.Vol.2,No.8.

Kotler, P. 2001. Manajemen Pemasaran di Indonesia, Jakarta Salemba Empat

Kotler, P. dan K.L. Keller. 2009. Manajemen Pemasaran. Edisi 13. Erlangga. Jakarta.

Kurniawan, D. dan Y.S. Kunto. 2013. Pengaruh Promosi dan Store Atmosphere Terhadap Impuls buying dengan Shoping Emotion Sebagai Variabel Intervening Studi Kasus di Matahari Departement Store Cabang Supermall Surabaya. Jurnal Manajemen Pemasaran 1(2) : 1-8.

Kurniawati, Devi dan RestutiSri. 2014. Pengaruh Sales Promotion Dan Store Atmosphere Terhadap Shopping Emotion Dan Impulse Buying Pada Giant Pekanbaru.Jurnal Tepak Manajemen Bisnis.6(3) pp: 24-37

Kusumawati, Andriani., Indra Wahyu Rahmawan., dan Srikandi Sumadji. 2013. Pengaruh Faktor-Faktor Lingkungan Toko terhadap Pembelian Impulsif. JurnalAdministrasi Bisnis, 6(2).

Levy, M., \& Weitz, B. A. 2001. Retailling Management (4th ed.). Richard D. Irwin Inc.

Levy, Michael., and Barton Weitz 2004. Retailing Management. International Edition. Fifth New York: McGraw-HilL Irwin.

Madjid, Rahmat. 2014. The Influence Store Atmosphere Towards Customer Emotions and Purchase Decisions. International Journal of Humanities and Social Science Invention. Vol. 3 Issue 10pp: 11-19

Margana, C.A. dan P.Y. Setiawan. 2014. Pengaruh Stimulus Lingkingan Toko Terhadap Perilaku Pembelian Tidak Terencana yang Dimediasi oleh Emosi Positif. Jurnal Manajemen. 3(9): 2615-2632.

Marianty, Resty. 2014. Pengaruh Keterlibatan Fahion Emosi Positif dan Kecenderungan Konsumsi Hedonik Terhadap Pembelian Impulsif. Tesis Jurusan Manajemen pada Fakultas Ekonomi Universitas Atmajaya Yogyakarta.

Mowen, John C. dan Michael Minor. 2002. Perilaku Konsumen. Alih Bahasa: Dwi Kartini Yahya. Jilid2. Jakarta: Penerbit Erlangga. 
A A Bagus Jambe Negara dan Ni Made Wulandari Kusumadewi, Pengaruh Atmosfer.....

Muruganantham, G. dan Bhakat, Ravi Shankar. 2013. A Review ofImpulse Buying Behavior.International Journal of Marketing Studies.Vol. 5, No. 3; 2013.

Naentiana, Putu Vera dan Setiawan, Putu Yudi. 2014. Peran Positive Emotion Dalam Memediasi Pengaruh Hedonic Shopping Value Terhadap Impulse Buying, Jurnal Nasional. pp: 2314-2332.

Nasir, Khoirun. 2010. Pengaruh Promosi Penjualan Dan Respon Emosi Terhadap Perilaku Pembelian Impulsif. Skripsi Fakultas Ekonomi Dan Bisnis UIN Syarif Hidayahtullah Jakarta.

Pattipeilohy, Victor Ringhard., Rofiati., and M. S. Idrus. 2013. The Influence of The Availability of Money and Time, Fashion Involvement, Hedonic Consumtion Tendency and Positive Emotion towards Impulse Buying Behavior in Ambon City. International Journal of Business and Behavioral Sciences. 3(8), pp: 36- 49.

Putra, Brian Permana. 2014. Analisis Pengaruh Promosi, Emosi Positif Dan Store Environment Terhadap Perilaku Impulse BuyingStudi Kasus pada Pelanggan Swalayan Tong Hien di Kota Semarang. Skripsi Jurusan Manajemen pada Fakultas Ekonomi dan Bisnis Universitas Diponogoro Semarang.

Rachmawati, Veronika. 2009. Hubungan Antara Hedonic Shopping Value, Positive Emotion, dan Perilaku Impulse Buying pada Konsumen Ritel. Majalah Ekonomi. Tahun XIX (2): hlm. 192-209.

Rittipant, Nattharika. 2013. Thai Consumer Response To SalesPromotions For Personal Care Products. International Conference on Engineering, Project, and Production Management .pp: 700-709

Sari, Dewa Ayu Taman. 2014. Merchandising, Promosi dan Atmosfer Toko Terhadap Impulse Buying Pelanggan Tiara Dewata Supermarket Denpasar. Jurnal Kewirausahaan, 3(4), pp: 851-967

Sari, T.A.D. dan A. Suryani. 2014. Pengaruh Merchandising, Promosi, dan Atmosfer Toko Terhadap Impulse Buying. Jurnal Manjemen. 3(4): 851867.

Sinaga, Inggrid., Suharyono., dan Snkandi Kumadji, 2012. Stimulus Store Environment dalam Menciptakan Emotional Response dan Pengaruhnya Terhadap Impulse Buying. Jurnal Administrasi Bisnis, 1(2), pp : 1-14. 
Sultan, A.J., Joireman, Jeff. And Sproot, D.E. 2012. Building Consumer SelfControl: The Effect of Self-Control Exercises on Impulse Buying Urges. Mark Lett, 23. pp: 61-73.

Suranta, Sembiring. 2013. Pengaruh Shopping Lifestyle dan Fashion Involvement terhadap Impulse Buying Behaviour. Jurnal Nasional. pp: 1-13

Tendai, Mariri dan Chipunza Crispen. 2009. In-store Shopping Environment and Impulsive Buying. African Journal of Marketing Management. Vol. 1 (4): pp. 102-108.

Utami, C.W.2010. Manajemen Ritel :Strategi dan Implementasi Operasional Bisnis Ritel Modern di Indonesia. Salemba Empat. Jakarta.

Vishnu, Parmar dan Raheem, Ahmed Rizwan. 2013. Factors Influencing Impulse Buying Behavior.European Journal Of Scientific Research. Vol. 100 No.3.

Yistiani, Manik Ni Nyoman., Ni Nyoman Kerti Yasa., dan I.G.A Ketut Gede Suasana. 2012. Pengaruh Atmosfer Gerai Dan Pelayanan Ritel Terhadap Nilai Hedonik Dan Pembelian Impulsif Pelanggan Matahari Department Store Duta Plaza Di Denpasar. Jurnal Manajemen Strategi Bisnis dan Kewirausahaan, 6(2),pp: 139-149

Yudatama. Aditya, Saryadi, dan Hari Susanto. 2009. Pengaruh Store Image, Store Atmospheric, Store Theatrics, dan Social Factors Terhadap Pembelian Tidak Terencana (Studi Kasus Pada Luwes Pasar Swalayan). Jurnal Ilmu Administrasi dan Bisnis. Universitas Diponegoro. 